\title{
Investigation of the tribological performance of ionic liquids in non-conformal EHL contacts under electric field activation
}

\author{
Michal MICHALEC ${ }^{1, *}$, Petr SVOBODA ${ }^{1}$, Ivan KRUPKA ${ }^{1,2}$, Martin HARTL ${ }^{1}$, Aleksandar VENCL ${ }^{3,4}$ \\ ${ }^{I}$ Faculty of Mechanical Engineering, Brno University of Technology, Brno 616 69, Czech Republic \\ ${ }^{2}$ Central European Institute of Technology, Brno University of Technology, Brno 612 00, Czech Republic \\ ${ }^{3}$ Faculty of Mechanical Engineering, University of Belgrade, Belgrade 111 20, Serbia \\ ${ }^{4}$ South Ural State University, Chelyabinsk 454080, Russia \\ Received: 21 August 2019 / Revised: 30 October 2019 / Accepted: 13 November 2019 \\ (C) The author(s) 2019.
}

\begin{abstract}
Real-time external alteration of the internal properties of lubricants is highly desirable in all mechanical systems. However, fabricating a suitable and effective smart lubricant is a long-lasting experimental process. In this study, the film thickness and frictional response of ionic liquid-lubricated non-conformal contacts to an electric field excitation under elastohydrodynamic conditions were examined. Film thickness was evaluated using a "ball-on-disc" optical tribometer with an electric circuit. Friction tests were carried on a mini traction machine (MTM) tribometer with a "ball-on-disc" rotation module and an electric circuit for contact area excitation. The results demonstrate that there is a difference in the behaviour of the ionic liquid during electric field excitation at the evaluated film thicknesses. The results of evaluated film thicknesses demonstrate that there is a difference in the behaviour of the ionic liquid during electric field excitation. Therefore, the ionic liquids could be a new basis for the smart lubrication of mechanical components. Moreover, the proposed experimental approach can be used to identify electrosensitive fluids.
\end{abstract}

Keywords: friction; thin film lubrication; electro-rheological fluid; smart fluid; lubrication

\section{Introduction}

In recent decades, an effort has been made to minimize friction in mechanisms to facilitate higher durability of contact surfaces and less energy consumption. The performance of a mechanism is strongly dependent on the composition, structure, and interaction of the lubricant with surrounding surfaces. Currently, with the expansion of the "Industry 4.0 " trend, there is an increasing desire to apply smart lubricants to conventional mechanical devices. Smart liquid lubricants are fluids whose rheological properties such as apparent viscosity change in the presence of a magnetic or electric field. Smart fluids are placed in two main categories according to the type of excitationmagnetorheological (MR) and electrorheological (ER) fluids [1]. ER fluids, especially natural ER fluids [2], such as ionic liquids, seem to be more suitable lubricants for the parts with non-conformal elements and mechanisms with thin-film lubrication regimes [2]. For natural ER fluids, a high external voltage was required to create sufficient electric intensity to induce changes [3]. Because the lubricating layer thickness is in the nanometre scale, a laboratory voltage supplying with the range of $20 \mathrm{~V}$ was satisfactory to induce noticeable changes in film thickness [4].

Natural ER fluids appear to be suitable smart substitutes for standard oil lubricants. One type of natural ER fluids is ionic liquids (ILs) - salts in liquid form containing organic or inorganic cations and anions with low melting points [5]. ILs have a neutral to bright yellow transparent appearance. They also have

* Corresponding author: Michal MICHALEC, E-mail: michal.michalec@vut.cz 
good chemical and thermal stabilities in addition to nonflammability [6]. Moreover, they are suitable for application in machines in high-vacuum environments and clean rooms because of their extremely low vapour pressure [7]. The viscosities of ionic liquids vary from 20 to $300 \mathrm{mPa} \cdot \mathrm{s}$ at $25^{\circ} \mathrm{C}$, depending on the fluid composition and structure [8-10].

The tribological performance of ionic liquids is related to their structure and properties as shown in Ref. [11]. Additionally, ionic liquids were observed as stable lubricants in extreme temperature conditions [12]. The performance of ionic liquid lubricant was better in samples with longer alkyl chains, which presents higher viscosity values and secures separation at high temperatures above $200{ }^{\circ} \mathrm{C}$ and at low temperatures at approximately $-30{ }^{\circ} \mathrm{C}$. The results demonstrate that the ionic liquids have lower friction and wear values compared with standard oils at all temperatures. Specifically, ionic liquid compounds have a remarkable effect in terms of preventing seizures in freshly generated metal surfaces [13]. On the other hand, considering the relatively high price of ionic liquids, their performance as additives has been examined. In fact, all the examined ionic liquids additives of $1 \mathrm{wt} \%$ in base oil have shown lower wear rates in comparison with the base oil lubrication [12]. As concluded from Ref. [14], ionic liquids as additives act as an effective wear and friction reductant in base oils, which is even more significant with the synergistic effect of zinc dialkyldithiophosphate (ZDDP). While the ZDDP additive can resist scuffing at room temperature, several ionic liquids additives have an antiscuffing and antiwear ability even at higher temperatures of approximately $100{ }^{\circ} \mathrm{C}$ [15].

An interesting attribute of ionic liquids, which has been observed, is their sensitivity to the presence of an external electric field [16, 17]. Because their molecule size is relatively smaller than the surface roughness, the size of asperities can significantly influence the ER effect of ionic liquids [18]. A study was conducted in the tribological field on a sliding friction comparison between a dry and IL-lubricated contact [19] where a strong influence of an applied electric current was observed. Despite the achieved changes in the coefficient of friction (COF), whether the difference is caused by the composition of ionic liquids or different behaviour of lubricated and dry contact is unclear. Another study examined film thickness excitation of ILs in elastohydrodynamic (EHD) conditions using an optical tribometer [4]. Noticeable changes in film thickness were obtained, although the temperature was neither measured nor discussed. As the lubricant viscosity exponentially decreases with temperature, temperature is an important parameter, as it indirectly affects the resulting film thickness. Furthermore, the conducting electricity might also contribute to the temperature increase. An interesting feature observed by Ref. [20] was the behaviour of micro-bubbles at different polarities of electric circuits in ionic liquidlubricated film. An experimental research on force microscopy using a nano-scale tip of $10 \mathrm{~nm}$ radius explained that the approaching of excitation body results in increase in repulsive force [21]; therefore, the closer the exciting bodies and the larger the excitation area, the higher the ionic liquid response, and the higher response of the ionic liquid is quantified in the repulsive or friction force. As reported, the polarity influenced the speed of collapsing of emerged bubbles, which has a considerable impact on bearings in electric environments; therefore, the ionic liquid tribological performance might also differ from the direction of an inverted electric circuit.

ILs have already been investigated with regard to all possible applications for lubrication in mechanical devices [11, 22, 23]. However, the performance of ILs as lubricants in tribology has predominantly been examined without measuring the temperature of the lubricant; investigations of the COF and lubricating layer thickness have been conducted independently, under slightly different conditions. Moreover, the frictional behavior of ionic liquids under charged conditions was studied in mixed or boundary conditions; thus, it is not entirely clear whether the electricity-formed chains were the main cause of the alternation of the COF. Therefore, experiments ought to be conducted on fully-formed liquid films with measurements of temperature being performed throughout the whole test so that all possible causes for the change of behaviour of the lubricating layer are considered. Thus far, a study focused on the frictional response of a fully formed lubricating layer to real-time polarity change during measurement has 
not been conducted. To understand the ER phenomenon of ionic liquids, an experimental comparative approach is necessary. In this study, the behaviour of an ionic liquid fluid film under electric field activation is observed. The performance of ionic liquid lubrication is investigated on two different devices to obtain a relation between the $\mathrm{COF}$ and the lubricating layer in the EHD regime, and the corresponding temperature for each measurement is also observed. The two devices used for the experiments are a "ball-on-disc" optical tribometer and a mini traction machine (MTM) tribometer with electric circuits connected to the ball and disc, respectively.

\section{Materials and methods}

\subsection{Experimental fluid}

The electrosensitive lubricant (ionic liquid) selected for measurements was 1-Butyl-3-Methylimidazolium hexafluorophosphate ([BMIM] $\mathrm{PF}_{6}$ ) with purity $\geqslant 97 \%$, which has already been reported to be rheologysensitive in the presence of electric fields [4]. As shown in Fig. 1, the ionic liquid is composed of anion and cation chains, also simply called alkyl chains. These chains differ in length and structure, and in whether they are branched or linear. Although the branched chains reportedly have a slightly higher viscosity depending on the temperature [10], the selected ionic liquid has a linear structure, assuming an orientation of linear alkyl chains that is simpler than that of ionic liquids with a branched structure.

To clarify the physical behaviour of ionic liquids in the presence of electric fields, a comparative approach was used to allow for the comparison of the obtained results with a non-electrosensitive lubricant. Because of significantly different characteristics of ionic liquids in comparison with standard oil lubricants, finding the oil with similar pressure-viscosity coefficient and viscosity was difficult. After considering the experiment

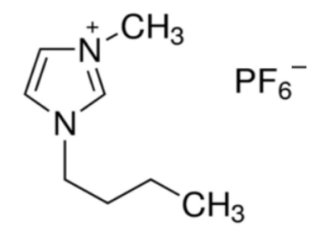

Fig. 1 Structure of [BMIM]PF ${ }_{6}$. design, the main deciding criterion for a reference oil was the absence of polarizable particles. Therefore, the mineral-based oil MA68 was chosen as a reference lubricant without additives and polarizable particles or chains. All measurements with the ionic liquid and oil were repeated under the same conditions so that the conclusions from the achieved results could be directly discussed. The measured properties of the selected ionic liquid and lubricant, required for calibration, evaluation, and prediction of lubricating regime, are listed in Table 1 . Viscosity was measured on a commercial Haake Roto-Visco viscosimeter. The refractive index value was obtained using the Abbe refractometer. Pressure-viscosity coefficients were evaluated according to the Hamrock-Dowson (H-D) central film thickness formula prediction [24] with data from an optical tribometer. All measurements were repeated three times.

\subsection{Experimental devices}

The comparative investigation of ionic liquid film excitation was carried out on two different experimental devices: Optical Tribometer for film thickness evaluation and Mini-Traction Machine for friction measurements.

\subsubsection{Film thickness evaluation}

Because both experimental fluids are transparent, an optical method for film thickness measurement could be applied. Therefore, experiments were carried out on the optical ball-on-disc tribometer, which is schematically shown in Fig. 2.

For the experiments, AISI 52100 (100Cr6 equivalent), which is a steel ball of grade 100 with a diameter of $25.4 \mathrm{~mm}$, was used. The second contact body was represented by a glass disc with a diameter of $150 \mathrm{~mm}$ and an optically smooth surface coated with an antireflexive (AR) layer for better light penetration. The elastic modulus of the steel ball was 212 GPa and that of the glass disc was $81 \mathrm{GPa}$. These values are

Table 1 Measured properties of experimental fluids at $25^{\circ} \mathrm{C}$.

\begin{tabular}{cccc}
\hline Sample & $\begin{array}{r}\text { Dynamic } \\
\text { viscosity, } \\
\eta(\mathrm{mPa} \cdot \mathrm{s})\end{array}$ & $\begin{array}{c}\text { Refractive } \\
\text { index, } n\end{array}$ & $\begin{array}{c}\text { Pressure-viscosity } \\
\text { coefficient, } \alpha \\
\left(\mathrm{GPa}^{-1}\right)\end{array}$ \\
\hline$[\mathrm{BMIM}] \mathrm{PF}_{6}$ & 247 & 1.410 & $4.9 \pm 0.3$ \\
MA68 & 137 & 1.483 & $20.8 \pm 1.3$ \\
\hline
\end{tabular}




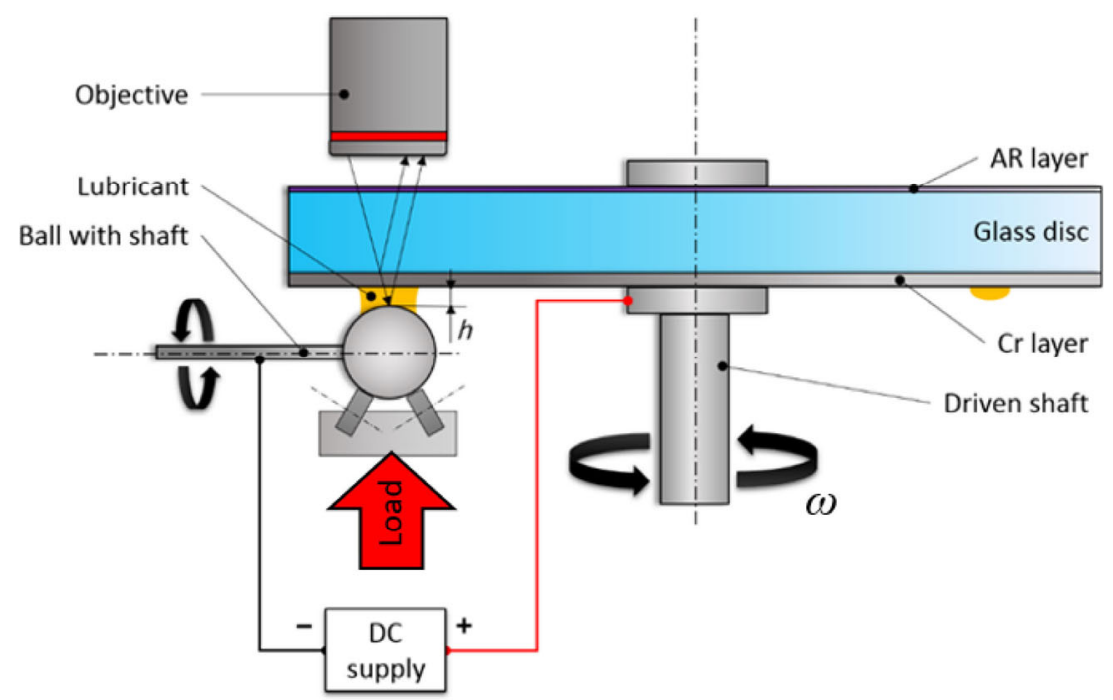

Fig. 2 Schematic representation of the optical tribometer with an excitation circuit.

listed in Table 2. Electricity from a laboratory supply was passed through the $10 \mathrm{~nm}$ thick chromium layer with a measured electric resistance of $32 \mathrm{k} \Omega$ from the driven shaft to the contact area. The polarity, as shown in Fig. 2, was preserved for all film thickness measurements.

The thickness of the lubricant film was evaluated using colorimetric interferometry [25]. In this technique, the digitized chromatic interferograms are after transformation from RGB to CIELAB colour space (internationally adopted Commission Internationale de l'Eclairage colorimetric reference system) converted to the film thickness map using appropriate colour matching algorithm and colour/film thickness calibration curves. By using optical interferometry, the film thickness in EHL contacts can be measured in the range between 1 and $800 \mathrm{~nm}$ with an accuracy of $\pm 1 \mathrm{~nm}$; thus, thin films and small changes in thickness could be observed.

Table 2 Optical tribometer contacting tribopair material properties.

\begin{tabular}{ccc}
\hline Property & Ball & Disc \\
\hline Material & $\begin{array}{c}\text { Bearing steel } \\
(100 \mathrm{Cr} 6)\end{array}$ & Glass (BK7) \\
Dimension (mm) & $\varnothing 25.4$ & $\varnothing 150$ \\
Young modulus (GPa) & 212 & 81 \\
Poisson ratio & 0.3 & 0.2 \\
Surface roughness, & 12 & $\begin{array}{c}\text { Optically } \\
\text { smooth }\end{array}$ \\
$R a(\mathrm{~nm})$ & &
\end{tabular}

\subsubsection{Friction measurements}

Friction measurements were carried out on a commercial MTM2 device with a contacting ball-on-disc tribopair (Fig. 3) for a relevant comparison with the results from the optical tribometer measurements.

The ball and the disc were both rotated independently to set the desired slide-to-roll ratio (SRR). The ball was mounted on the loading arm with a friction force sensor. This arm was automatically regulated by software. The COF was then calculated from the normal force FN and the friction force. For the minimum consumption of purchased ionic liquid, a small disc specimen with a tub was selected for the measurements. The material properties of the MTM contacting bodies are listed in Table 3. The contact area excitation was carried out using the laboratory power source with respect to polarity, as seen in Fig. 3.

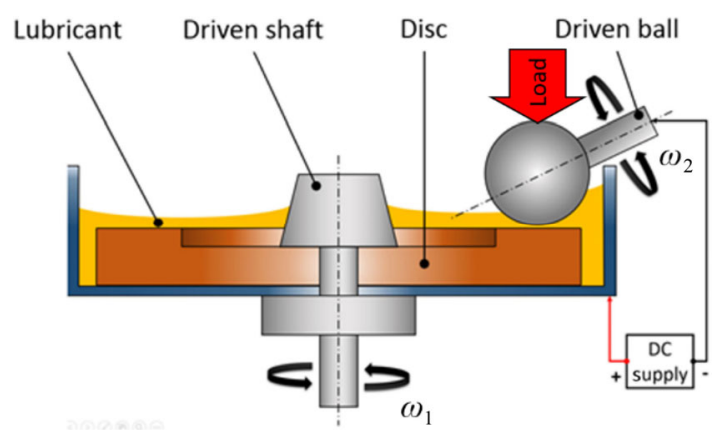

Fig. 3 Schematic representation of MTM contact tribopair with excitation circuit. 
Table 3 MTM contacting tribopair material properties.

\begin{tabular}{ccc}
\hline Property & Ball & Disc \\
\hline Material & Steel $(\mathrm{C} 10)$ & Steel $(\mathrm{C} 45)$ \\
Dimensions $(\mathrm{mm})$ & $\varnothing 12.7\left(1 / 2^{\prime \prime}\right)$ & $\varnothing 32$ \\
Young modulu $(\mathrm{GPa})$ & 200 & 200 \\
Poisson ratio & 0.3 & 0.3 \\
Surface roughness, $R a(\mathrm{~nm})$ & 15 & 10 \\
\hline
\end{tabular}

\subsubsection{Lubrication regime prediction}

Experimental conditions for both measurements were set according to the $\mathrm{H}-\mathrm{D}$ film thickness prediction formula [24]:

$$
h_{\min }=R^{\prime} \cdot\left[3.63 U^{0.68} G^{0.49} W^{-0.073}\left(1-\mathrm{e}^{-0.68 k}\right)\right]
$$

where $R^{\prime}$ is the reduced radius of curvature, $U$ is dimensionless speed parameter, $G$ is a dimensionless material parameter, $W$ is a dimensionless load parameter, and $k=a / b$ is a dimensionless ellipticity parameter.

$$
U=\frac{\eta_{0} u}{E^{\prime} R^{\prime}}
$$

taking into account the atmospheric lubricant viscosity $\eta_{0}$, entertainment speed $u$, and reduced modulus of elasticity $E^{\prime}$ :

$$
G=E^{\prime} \alpha
$$

$G$ considers the pressure-viscosity coefficient $\alpha$.

$$
W=\frac{F}{E^{\prime} R^{\prime 2}}
$$

where $F$ is the normal applied load.

The lubrication regime was then identified using the dimensionless lubrication parameter $\lambda$ from Eq. (5):

$$
\lambda=\frac{h_{\min }}{\sqrt{R_{\mathrm{q} 1}{ }^{2}+R_{\mathrm{q} 2}{ }^{2}}}
$$

where $R_{\mathrm{q} 1}$ and $R_{\mathrm{q} 2}$ are the root mean square roughness of the contacting surfaces.

The desired lubrication parameter for measurements was $3<\lambda<10$, represented as the EHL regime when contacting surfaces are separated by a fully formed lubricating film [26].

\section{Results and discussion}

The main assumption for excitation of the fluid film was to achieve a complete separation of contacting bodies with a coherent lubricating film; therefore, all measurements were designed for the lubrication parameter $\lambda \approx 7$. Thus, the results from both experimental devices could be compared and discussed afterwards.

\subsection{Measurement of film thickness}

The measurement with excitation was carried out on a "ball-on-disc" optical tribometer at the load of $20 \mathrm{~N}$ (Hertzian pressure is approximately $450 \mathrm{MPa}$ ) and a speed of $200 \mathrm{~mm} \cdot \mathrm{s}^{-1}$ (pure rolling with $3 \%-6 \% \mathrm{SRR}$ ), set according to the H-D prediction for lubrication parameter value $\lambda \approx 7$.

The experimental fluid was spread on the track to avoid starvation of the contact area. The approximate amount of experimental fluids used for each film thickness measurement was $2 \mathrm{~mL}$. The voltage was increased and held at the set value for several seconds to let the disc fully rotate at least once before capturing the interferogram. At each voltage, three interferograms were captured and evaluated. The optical tribometer measurement of MA68 did not indicate an observable difference in the film thickness with excitation. The central film thickness of oil was $265 \mathrm{~nm}$ and the minimum film thickness was $125 \mathrm{~nm}$ during the whole measurement (Fig. 4). In contrast, the ionic liquid showed noticeable changes in film thickness, as seen in Fig. 4. The observable difference in the minimum film thickness was measured at an external voltage of $10 \mathrm{~V}$. The central film thickness exhibited a relatively small increase up to $15 \mathrm{~V}$. A stronger response to a lower electric field was observed in the minimum film thickness compared with the central film thickness of the [BMIM] $\mathrm{PF}_{6}$ ionic liquid owing to the higher intensity of the electric field in the smaller gap between the contacting bodies. As the voltage was increased, the electric field in the central area reached an intensity sufficient to induce the ER effect in the lubricating layer of the ionic liquid. As shown in Fig. 4, the oil film thickness of MA68 was globally higher than that of the IL; this is due to the significantly higher pressure-viscosity coefficient of the oil. 

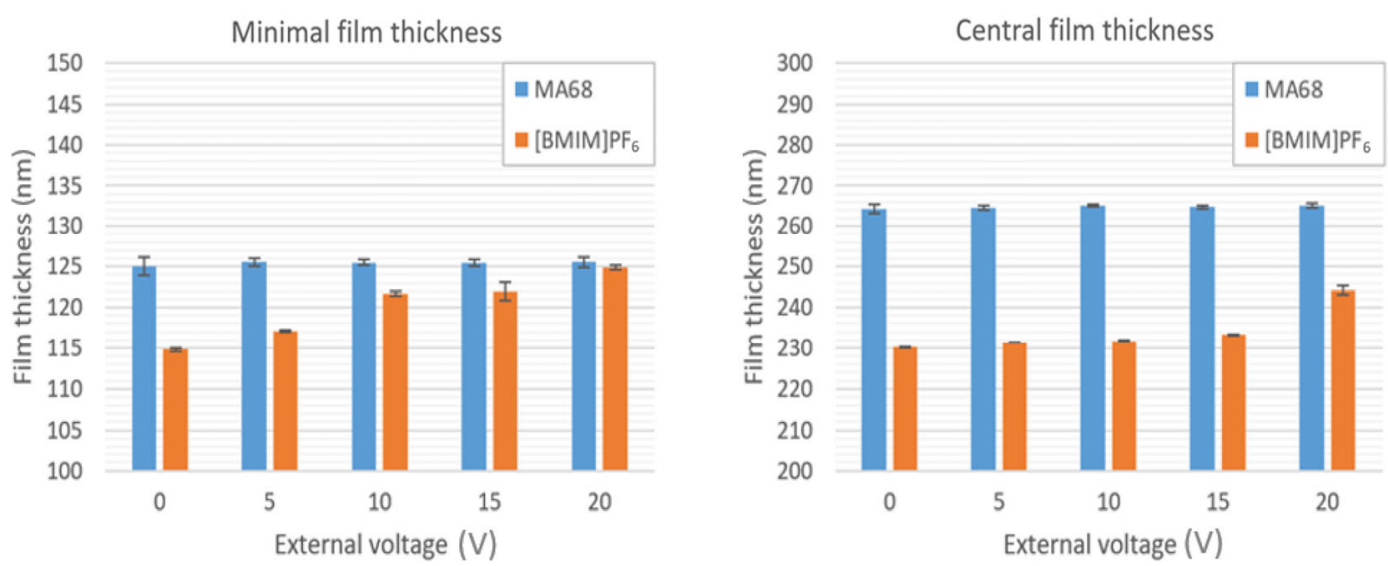

Fig. 4 Results of film thickness measurements with applied voltage.

Subsequently, the minimum film thickness slightly increased to the value of $125 \mathrm{~nm}$, which makes an approximate $10 \mathrm{~nm}$ increase in the film thickness at $20 \mathrm{~V}$ compared to $0 \mathrm{~V}$. At $20 \mathrm{~V}$, a noticeable increase in the value of the central film thickness was measured. The difference in central film thickness between 20 and $0 \mathrm{~V}$ was approximately $15 \mathrm{~nm}$ (Fig. 5). The maximum applied external voltage was $20 \mathrm{~V}$ because, by the end of the measurements with the $20 \mathrm{~V}$ excitation, white stripes near the contact on interferograms were observed; thus, the measurement was terminated. Although the increase in the minimal and central film thickness was in the range of the surface roughness of the contacting bodies, no fluctuations in film thickness was observed; therefore, the influence of surface roughness can be considered insignificant.
Despite the increase in the recorded film thickness of the ionic liquid during the electric field excitation, a destructive effect of ionic liquid excitation was observed on the chromium layer of the glass disc (Fig. 6); this could have been caused by electrochemical processes [27, 28]. Moreover, the damage might be the result of corrosion due to the halogen ionic liquid, accelerated by the electric field [29]. It remains unclear whether the destructive processes occurred at lower voltages as well; however, the increasing voltage apparently intensified the damage of the chromium layer. The width of the damaged area is remarkably larger than that of the contact area; therefore, it is clear that the electric charge was conducted farther away from the area of contact with the ionic liquid. This destructive process evidently continued even

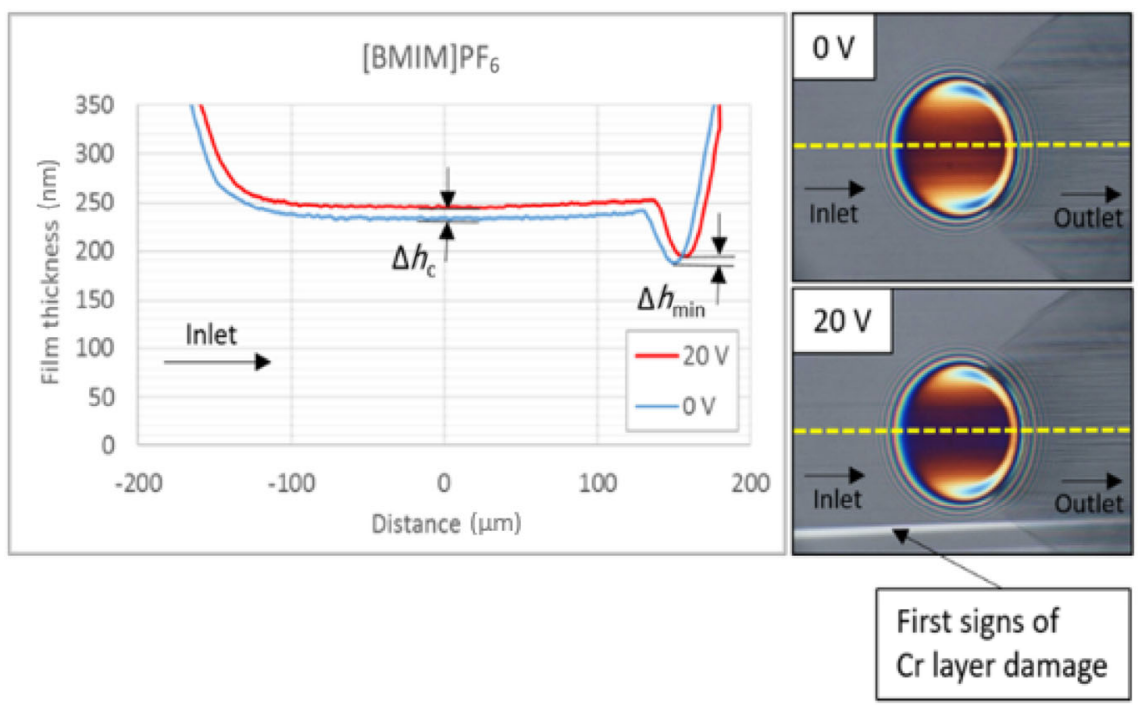

Fig. 5 Film thickness comparison of [BMIM]PF 6 at 0 and $20 \mathrm{~V}$. 


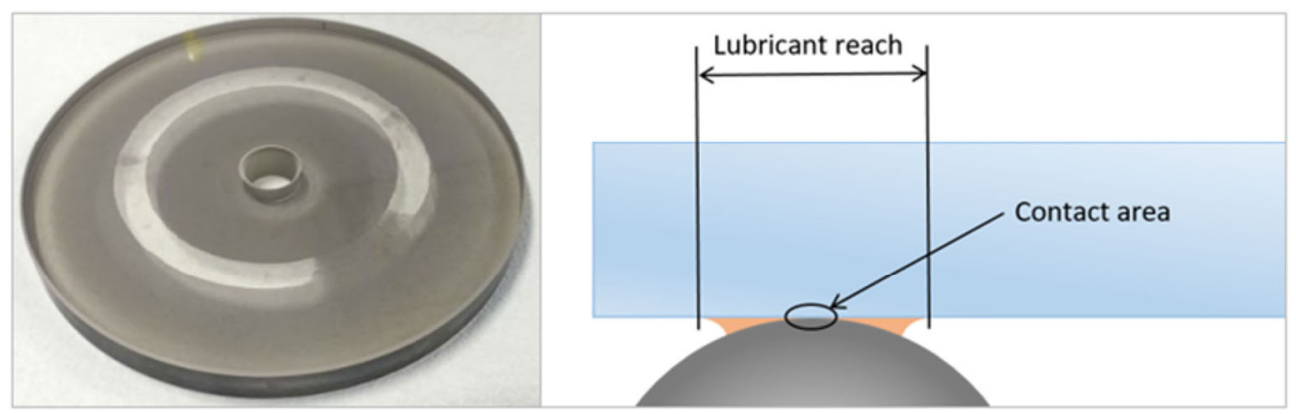

Fig. 6 (a) Damaged chromium layer of glass disc after ionic liquid excitation and (b) schematic of the scar width developed along the reach of the charged lubricant.

after the electric circuit was disconnected, until the remaining ionic liquid was cleaned. Therefore, the ionic liquid possibly remained in an excited state for some time even after the electric field was no longer active; this was evident from the lower intensity of the chromium layer damage at the sites where only a small amount of the ionic liquid remained after the experiment.

Throughout the measurement with excitation, a thermometer at the outlet did not indicate any significant change in the lubricant temperature, which remained at $25.5-26{ }^{\circ} \mathrm{C}$. The electric current passing through the MA68 oil at $20 \mathrm{~V}$ could not be measured using a standard ammeter because of the high resistivity of the chromium disc and low conductivity of the oil. For the ionic liquid, the value of the measured electric current at $20 \mathrm{~V}$ was $0.5 \mathrm{~mA}$. Considering the voltage drop caused by the chromium layer, the actual voltage induced on the contact area was $4 \mathrm{~V}$, creating an electric intensity of $32 \mathrm{MV} \cdot \mathrm{m}^{-1}$ within the minimum film thickness.

\subsection{Friction tests}

The MTM tribometer was used for the friction tests with excitation. Experimental parameters were set to a $5 \mathrm{~N}$ load (Hertzian pressure $\sim 660 \mathrm{MPa}$ ) and $400 \mathrm{~mm} \cdot \mathrm{s}^{-1}$ speed according to the $\mathrm{H}-\mathrm{D}$ prediction for the lubrication parameter $\lambda \approx 7$. Because a small sliding of the ball occurs during the operation with the optical tribometer, a slight slide-to-roll ratio (SRR) of $6 \%$ had to be applied to slightly increase the COF so that results with better resolution could be obtained. To achieve fully flooded conditions, $6 \mathrm{~mL}$ of experimental fluid was poured into the reservoir for individual measurement. To avoid the results being distorted by residual charge and other effects, the fluid was replaced for each experiment. Two tests were performed - the time test with repeated voltage switch-off to investigate the response of the experimental lubricants to excitation, and the polarity change test where the input polarity was switched at a certain moment so that the assumption about the detachment of the ordering layers according to the polarity of contacting bodies could be observed.

The time test was carried out with external DC voltage supply attached to the contacting bodies, repeatedly activated and deactivated for $30 \mathrm{~s}$ with a maximal voltage of $0.5 \mathrm{~V}$ allowed for contact bodies and a measured electric current of $0.008 \mathrm{~A}$. As shown in Fig. 7, no noticeable response was observed of the COF to the electric circuit activation and deactivation, respectively, throughout the entire measurement with MA68 oil and the total temperature change of the lubricant at the outlet area for single measurement was lower than $0.5^{\circ} \mathrm{C}$.

Similarly, with the ionic liquid, the maximal voltage allowed to contact the bodies was $0.5 \mathrm{~V}$; however, the measured electric current reached $0.42 \mathrm{~A}$. In contrast with the MA68 oil, the results obtained with the [BMIM] $\mathrm{PF}_{6}$ ionic liquid showed a jump-like increase and decrease of the COF, respectively, according to the applied voltage, as seen in Fig. 8. Moreover, the total temperature changes of the lubricant at the outlet area for single measurement did not exceed $0.5{ }^{\circ} \mathrm{C}$, which clearly indicates that the behaviour of the selected ionic liquid can be controlled externally because, at the moment of electric circuit activation and deactivation, a noticeable instant change occurs. 


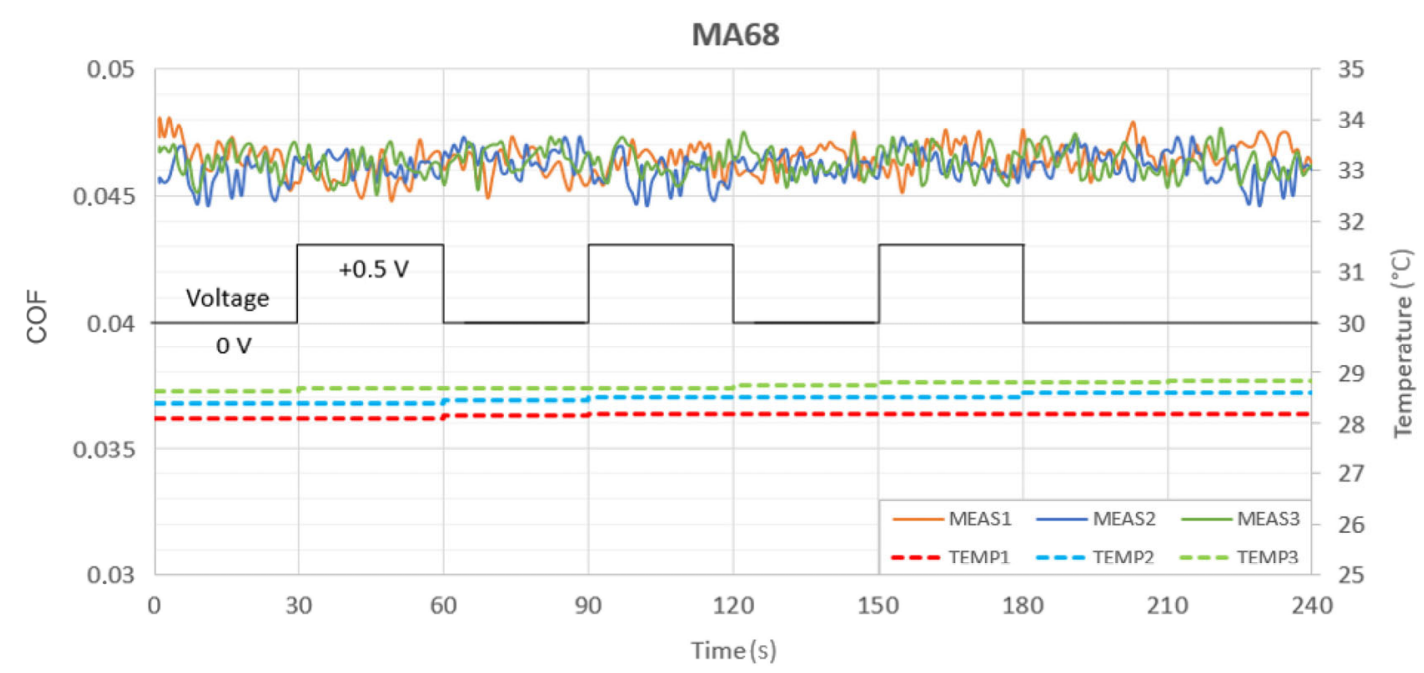

Fig. 7 MA68 oil COF and temperature dependence on voltage change.

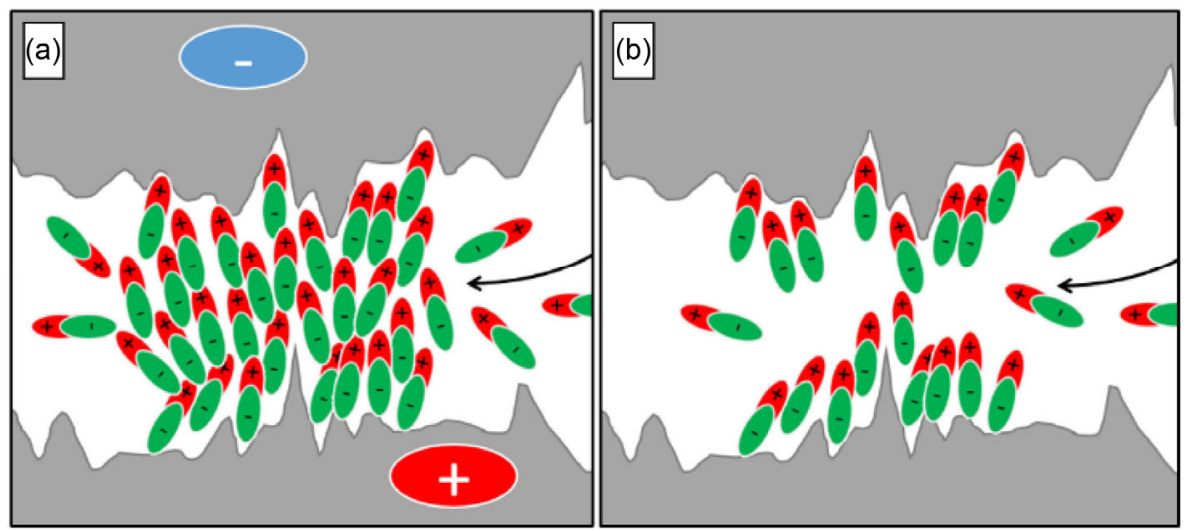

Fig. 8 Schematic of ionic liquid alkyl chain behaviour (a) during excitation and (b) after excitation.

The difference in COFs between the initial and final values could be caused by layers of the residual alkyl chain ordered at contacting surfaces that remained even after the electric circuit was disconnected, as schematically shown in Fig. 8. Moreover, as stated in Ref. [30], the ionic liquid evidently acquires a solid-like structure due to a strong attraction at a charged electrode surface, what results in an increased friction force caused by bonding forces of excited and arranged ion-pair layers, what is typical for ionic liquids between charged surfaces [31]. In contrast, the unexcited state of the ionic liquid has a liquid-like structure, and therefore the bonding forces are significantly smaller. The link can be seen in Fig. 9, where the COF at the final stage of measurement (from $180 \mathrm{~s}$ until the end) is higher than the initial value during the first $30 \mathrm{~s}$ of the experiments. The lowering trend during the final stage indicates that the attraction of layers close to the surface remains for a certain period but tends to converge to the initial state over time.

The polarity change test was performed under constant conditions without connecting the electric circuit for $240 \mathrm{~s}$. Subsequently, the electric circuit was activated for $240 \mathrm{~s}$ and the polarity was purposely switched, so that the explanation of the ionic liquid ordered layer for rheology adjustment during excitation could be verified [4]. The final phase of the time test, when the electric circuit was switched off, was to demonstrate a possible effect of the ionic liquid residual charge on the $\mathrm{COF}$, as observed in time tests. Similarly, during the previous measurements, the MA68 oil did not indicate any significant difference in the value of COF during the time test with excitation, as seen in Fig. 10. In contrast to the MA68

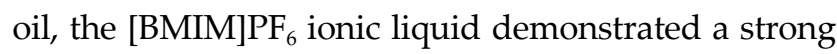
response to the applied electric field during the 


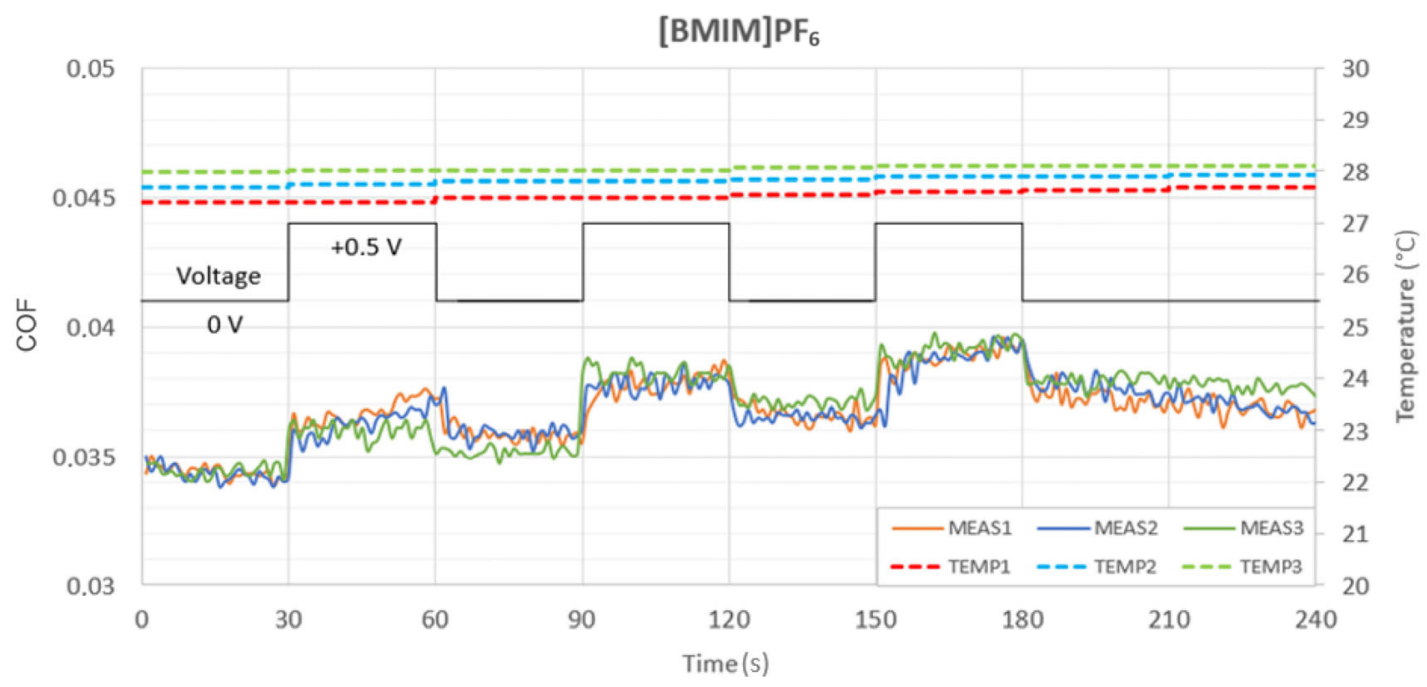

Fig. $9[\mathrm{BMIM}] \mathrm{PF}_{6} \mathrm{COF}$ and temperature dependence on voltage change.

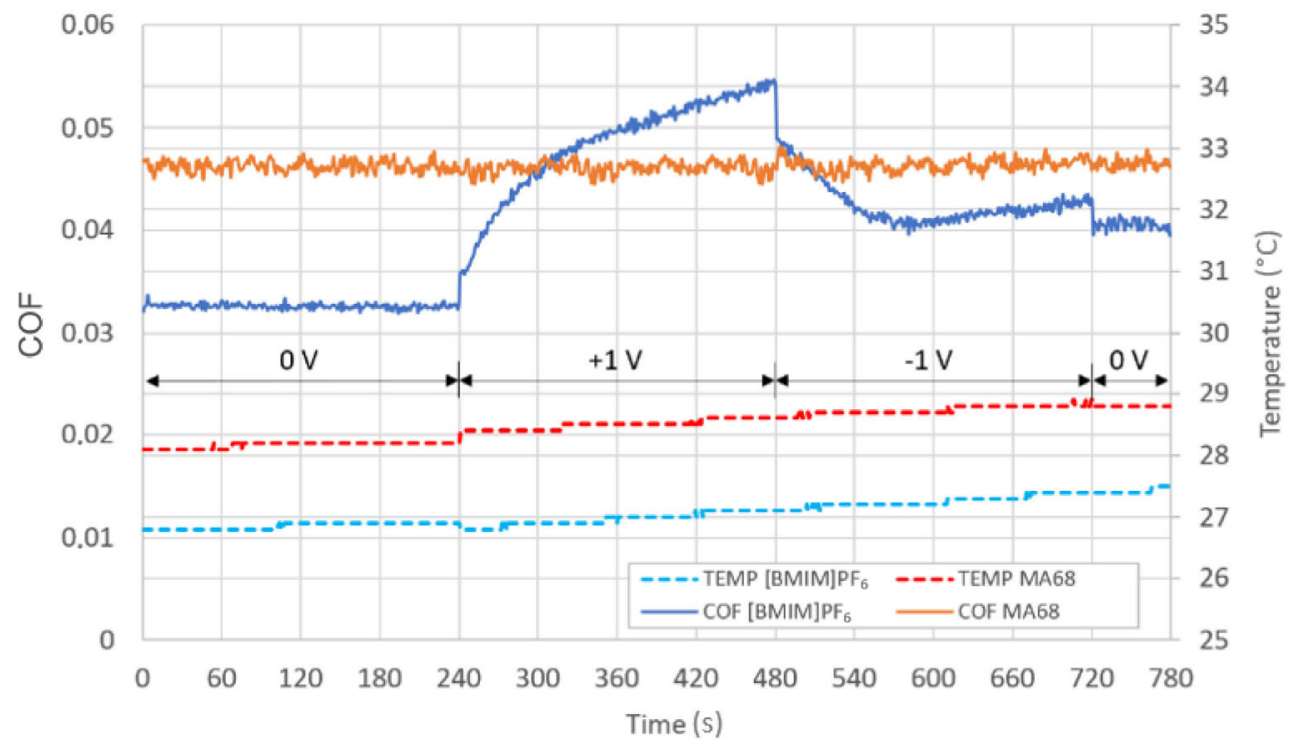

Fig. 10 MA68 and [BMIM] $\mathrm{PF}_{6} \mathrm{COF}$ and temperature dependence on voltage.

excitation phase (Fig. 10). Within the unexcited phase, a relatively stable COF was measured. At the moment of the electric circuit activation, an instant increase in the COF was observed. The value of the COF continuously increased until the polarity switch at $480 \mathrm{~s}$, when an instant decrease was recorded. Subsequently, the value of the COF decreased at approximately $580 \mathrm{~s}$, while the ionic liquid exhibited the reverse effect on the COF with $-1 \mathrm{~V}$ than in the interval of $+1 \mathrm{~V}$ electric circuit, such that the electricity-induced behavior of ionic liquid excitation was reversible to a certain extent [32]. However, the already adsorbed particles to the surface might have accelerated the polarity change process and retain the COF at a higher value than in the initial phase. Subsequently, the COF started a slight rise, which can be plainly explained as a recurrent orientation and cumulation of the alkyl chain in agreement with the shifted polarity. Once the circuit was disconnected, another instant decrease was observed that continued in a monotonous trend. The final phase without the activated electric field had a relatively monotonous trend; however, the COF remained at a considerably higher value than at the beginning of the test. Because the temperature differed by only approximately $0.8^{\circ} \mathrm{C}$ throughout the whole measurement, a higher value 
of COF can be explained as a result of the remaining alkyl chain layers at the ball and disc surfaces (Fig. 9); similarly, as was clarified within the time test.

The measured electric current during the MA68 oil excitation was $0.016 \mathrm{~A}$ at a voltage of $1 \mathrm{~V}$ in the circuit. In the circuit closed by the ionic liquid lubricating film, an electric current of $0.84 \mathrm{~A}$ was observed. Compared with the MA68 oil, the voltage was significantly higher. This confirms that the IL has a relatively good conductivity and sensitivity to electricity as ILs are liquid salts composed of anions and cations. Throughout all the friction measurements, the temperature of the lubricant was recorded at the outlet. The total temperature change over the whole measurement was $2{ }^{\circ} \mathrm{C}$ for MA68 and $1.5{ }^{\circ} \mathrm{C}$ for

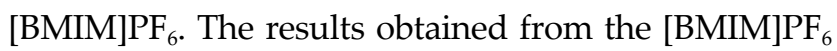
measurements eliminated the influence of temperature as a dominant factor in adjusting lubricant performance. Therefore, the orientation and cumulating of the ionic liquid alkyl chains and layers [33, 34] could be responsible for the phenomenon of electricity-induced external control of the smart lubricant rheology and lubricating layer behavior (Fig. 8(a)).

The measurements with the optical tribometer and the MTM tribometer exhibited similar behaviour in the results for the ionic liquid-significant changes in film thickness and COF with electricity activation during the operation in the EHD lubrication regime. In contrast to the fluid without polarizable particles or chains, the MA68 oil did not exhibit any noticeable changes in film thickness and $\mathrm{COF}$, respectively. Moreover, the temperature difference measured for all tests was considerably small, in the range of $1{ }^{\circ} \mathrm{C}$. These findings support the fact or assumption that the temperature had a negligible effect on the observed parameters, and they also prove that the selected ionic liquid has an electrotuneable tribological behavior, represented by the lubricating film thickness and COF, respectively. In addition, the polarity change test demonstrated that controlling the value of COF by the orientation of electric circuit is possible; therefore, ionic liquids are a prospective, externally controlled bearing lubricant. Further research could focus on the active control of film thickness through polarity alternation using similar approaches as presented in this study; however, it should be conducted with consideration to a suitable method for preventing the chromium layer damage.

\section{Conclusions}

This study has presented an experimental investigation of $[\mathrm{BMIM}] \mathrm{PF}_{6}$ ionic liquid behavior in charged nonconformal contacts. Results obtained by different methods under similar EHD conditions were compared, discussed, and the following concluding remarks were derived:

1) A $15 \mathrm{~nm}$ increase is recorded in the thickness of the $[\mathrm{BMIM}] \mathrm{PF}_{6}$ film in the presence of an electric field.

2) A noticeable destructive effect of the electricityexcited ionic liquid on chromium layer of the glass disc, possibly caused by the character of experimental fluid. Further research on excitation behavior using halogen-free ionic liquids might help to clarify the destructive process of thin metal layers throughout the lubricating film thickness measurement period.

3) A strong electric field and polarity influence of the ionic liquid [BMIM] $\mathrm{PF}_{6}$ was observed during friction measurements resulting in an instant increase and decrease in the COF. This proved the possibility to control the behavior of the ionic liquid lubricating layer externally, using an electric field created between the contacting elements separated by a coherent fluid film.

4) The inspected change of lubricant temperature was relatively small throughout all measurements. Moreover, the ionic liquid results exhibited significant changes in behavior during the activation and deactivation of electric circuit, respectively. Therefore, the temperature influence was eliminated as the main cause of alternation in the film thickness and COF.

5) The proposed methodology can be used to determine the electrorheology type of a substance depending on whether there is an increase or a decrease in the film thickness and COF, and whether an examined substance has a positive or negative ER effect.

\section{Acknowledgements}

This research was carried out under the CEITEC 2020 project (LQ1601) with financial support from the 
Ministry of Education, Youth and Sports of the Czech Republic under the National Sustainability Programme II and the project FSI-S-17-4415 with financial support from the Ministry of Education, Youth and Sports of the Czech Republic. Aleksandar VENCL acknowledges the projects TR 34028 and TR 35021, financially supported by the Republic of Serbia, Ministry of Education, Science and Technological Development.

Open Access This article is licensed under a Creative Commons Attribution 4.0 International License, which permits use, sharing, adaptation, distribution and reproduction in any medium or format, as long as you give appropriate credit to the original author(s) and the source, provide a link to the Creative Commons licence, and indicate if changes were made.

The images or other third party material in this article are included in the article's Creative Commons licence, unless indicated otherwise in a credit line to the material. If material is not included in the article's Creative Commons licence and your intended use is not permitted by statutory regulation or exceeds the permitted use, you will need to obtain permission directly from the copyright holder.

To view a copy of this licence, visit http://creativecommons.org/licenses/by/4.0/.

\section{References}

[1] Stanway R. Smart fluids: Current and future developments. Mater Sci Technol 20(8): 931-939 (2004)

[2] Michalec M, Svoboda P, Krupka I, Hartl M. Tribological behaviour of smart fluids influenced by magnetic and electric field-A review. Tribol Ind 40(4): 515-528 (2018)

[3] Matsumura Y, Shiraishi T, Morishita S. Stiffness and damping of liquid crystal lubricating film under electric field. Tribol Int 54: 32-37 (2012)

[4] Xie G X, Luo J B, Guo D, Liu S H. Nanoconfined ionic liquids under electric fields. Appl Phys Lett 96(4): 043112 (2010)

[5] Dupont J, De Souza R F, Suarez P A Z. Ionic liquid (molten salt) phase organometallic catalysis. Chem Rev 102(10): 3667-3692 (2002)

[6] Lei Z G, Chen B H, Koo Y M, MacFarlane D R. Introduction: Ionic liquids. Chem Rev 117(10): 6633-6635 (2017)

[7] Ngo H L, LeCompte K, Hargens L, McEwen A B. Thermal properties of imidazolium ionic liquids. Thermochim Acta 357-358: 97-102 (2000)

[8] Jacquemin J, Husson P, Padua A A H, Majer V. Density and viscosity of several pure and water-saturated ionic liquids. Green Chem 8(2): 172-180 (2006)

[9] Gao M, Ma L R, Luo J B. Effect of alkyl chain length on the orientational behavior of liquid crystals nano-film. Tribol Lett 62(2): 24 (2016)

[10] Xue L J, Gurung E, Tamas G, Koh Y P, Shadeck M, Simon S L, Maroncelli M, Quitevis E L. Effect of alkyl chain branching on physicochemical properties of imidazoliumbased ionic liquids. J Chem Eng Data 61(3): 1078-1091 (2016)

[11] Minami I. Ionic liquids in tribology. Molecules 14(6): 2286-2305 (2009)

[12] Bermúdez M D, Jiménez A E, Sanes J, Carrión F J. Ionic liquids as advanced lubricant fluids. Molecules 14(8): 28882908 (2009)

[13] Zhou F, Liang Y M, Liu W M. Ionic liquid lubricants: Designed chemistry for engineering applications. Chem Soc Rev 38(9): 2590-2599 (2009)

[14] Zhou Y, Qu J. Ionic liquids as lubricant additives: A review. ACS Appl Mater Interfaces 9(4): 3209-3222 (2017)

[15] Xiao H P. Ionic liquid lubricants: Basics and applications. Tribol Trans 60(1): 20-30 (2017)

[16] English N J, Mooney D A, O'Brien S. Ionic liquids in external electric and electromagnetic fields: A molecular dynamics study. Mol Phys 109(4): 625-638 (2011)

[17] Fajardo O Y, Bresme F, Kornyshev A A, Urbakh M. Electrotunable lubricity with ionic liquid nanoscale films. Sci Rep 5: 7698 (2015)

[18] David A, Fajardo O Y, Kornyshev A A, Urbakh M, Bresme F. Electrotunable lubricity with ionic liquids: The influence of nanoscale roughness. Faraday Discuss 199: 279-297 (2017)

[19] Huang W, Kong L L, Wang X L. Electrical sliding friction lubricated with ionic liquids. Tribol Lett 65(1): 17 (2017)

[20] Xie G X, Si L N, Guo D, Liu S H, Luo J B. Interface characteristics of thin liquid films in a charged lubricated contact. Surf Interface Anal 47(3): 315-324 (2015)

[21] Somers A E, Howlett P C, MacFarlane D R, Forsyth M. A review of ionic liquid lubricants. Lubricants 1(1): 3-21 (2013)

[22] Cooper P K, Li H, Rutland M W, Webber G B, Atkin R. Tribotronic control of friction in oil-based lubricants with ionic liquid additives. Phys Chem Chem Phys 18(34): 23657-23662 (2016)

[23] Hoth J, Hausen F, Müser M H, Bennewitz R. Force microscopy of layering and friction in an ionic liquid. 
J Phys: Condens Matter 26(28): 284110 (2014)

[24] Hamrock B J, Dowson D. Isothermal elastohydrodynamic lubrication of point contacts: Part III-fully flooded results. J Lubr Technol 99(2): 264-275 (1977)

[25] Hartl M, Krupka T, Poliščuk R, Liška M, Molimard J, Querry M, Vergne P. Thin film colorimetric interferometry. Tribology Transactions 44(2): 270-276 (2001)

[26] Stribeck R. Die wesentlichen Eigenschaften der Gleit- und Rollenlager. Berlin (Germany): Springer, 1903.

[27] Abbott A P, Frisch G, Hartley J, Karim W O, Ryder K S. Anodic dissolution of metals in ionic liquids. Prog Nat Sci: Mater Int 25(6): 525-602 (2015)

[28] Abbott A P, Capper G, Davies D L, Rasheed R K, Archer J, John C. Electrodeposition of chromium black from ionic liquids. Trans IMF 82(1-2): 14-17 (2004)

[29] Totolin V, Pisarova L, Dörr N, Minami I. Tribochemistry and thermo-oxidative stability of halogen-free ionic liquids.

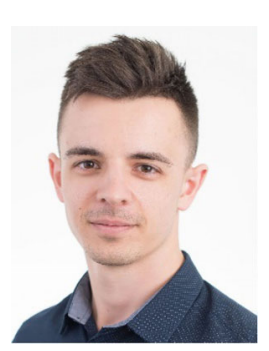

Michal MICHALEC. He received his M.S. degree in mechanical engineering from Brno University of Technology, Czech Republic, in 2019. His current position is a junior researcher and a member of Elastohydrodynamic Lubrication

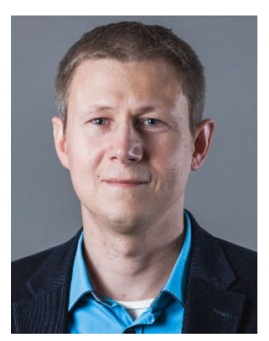

Petr SVOBODA. He received his M.S. and Ph.D. degrees in mechanical engineering from Brno University of Technology, Czech Republic, in 2005 and 2009, respectively. His current position is an associate professor and a

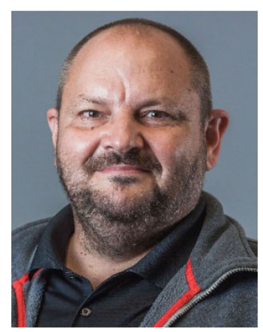

Ivan KRUPKA. He received his M.S. and Ph.D. degrees in mechanical engineering from Brno University of Technology, Czech Republic, in 1990 and 1997, respectively. His current position is a professor and
RSC Adv 7(77): 48766-48776 (2017)

[30] Pivnic K, Fajardo O Y, Bresme F, Kornyshev A A, Urbakh M. Mechanisms of electrotunable friction in friction force microscopy experiments with ionic liquids. J Phys Chem C 122(9): 5004-5012 (2018)

[31] Perkin S. Ionic liquids in confined geometries. Phys Chem Chem Phys 14(15): 5052-5062 (2012)

[32] Zhang F, Xie G X, Pan J S. Tunable adsorption and film formation of mussel adhesive protein by potential control. Langmuir 33(35): 8749-8756 (2017)

[33] Fajardo O Y, Bresme F, Kornyshev A A, Urbakh M. Electrotunable friction with ionic liquid lubricants: How important is the molecular structure of the ions? J Phys Chem Lett 6(20): 3998-4004 (2015)

[34] Kong L L, Huang W, Wang X L. Ionic liquid lubrication at electrified interfaces. J Phys D: Appl Phys 49(22): 225301 (2016)

Section at Tribology Group, Institute of Machine and Industrial Design, Faculty of Mechanical Engineering, Brno University of Technology. His research areas cover the boundary, mixed, and elastohydrodynamic lubrication, rheology of ionic liquids, friction, and wear.

member of Elastohydrodynamic Lubrication Section at Tribology Group, Institute of Machine and Industrial Design, Faculty of Mechanical Engineering, Brno University of Technology. His research areas cover the boundary, mixed, and elastohydrodynamic lubrication, starvation, surface texturing effect, and lubricant rheology.

head of Tribology Group, Institute of Machine and Industrial Design, Faculty of Mechanical Engineering, Brno University of Technology. His research areas cover the mixed and elastohydrodynamic lubrication, surface texturing effect, and lubricant rheology. 


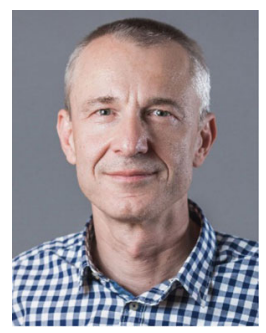

Martin HARTL. He received his M.S. and Ph.D. degrees in mechanical engineering from Brno University of Technology, Czech Republic, in 1990 and 1997, respectively. His current position is a professor and

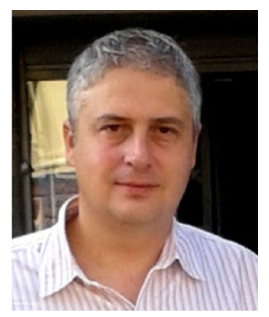

Aleksandar VENCL. He received his M.S. degree in engineering materials in 2002 and Ph.D. degree in tribology in 2008 from the Faculty of Mechanical Engineering at University of Belgrade, Republic of Serbia. His current position is a full professor and head of Tribology Laboratory at head of Institute of Machine and Industrial Design, Faculty of Mechanical Engineering, Brno University of Technology. His research areas cover the boundary, mixed, and elastohydrodynamic lubrication, roughness effect, and biotribology.

Faculty of Mechanical Engineering, University of Belgrade. His main research fields are friction and wear characteristics of materials (metals, polymers, ceramics, and composites), surface modifications and coatings, lubricants (application, recycling, and monitoring), nanotribology, and failure diagnostic of tribological systems. 